\title{
Aplikasi Pembelajaran Pengenalan Huruf, Angka, Warna dan Bentuk Bangun Datar Pada Siswa Kelas 1 SDN 5 Parittiga Berbasis Android
}

\author{
Sundari \\ Program Studi Teknik Informatika \\ STMIK Atma Luhur \\ Jln. Jend Sudirman - Selindung PangkalPinang \\ upin_nya@ymail.com
}

\author{
Delpiah Wahyuningsih \\ Program Studi Teknik Informatika \\ STMIK Atma Luhur \\ Jln. Jend Sudirman - Selindung PangkalPinang \\ delphibabel@atmaluhur.ac.id
}

\begin{abstract}
Para orang tua cukup sulit untuk membimbing anak-anaknya belajar, karena ketidaktertarikan anak yang merasa bosan dengan media belajar (buku). Untuk meningkatkan semangat anak belajar dengan media pembelajaran yang moveable (mudah dibawa kemana-mana) dan dengan tampilan yang menarik, diharapkan dapat membantu para orang tua untuk mengajak anak belajar di rumah dan membantu anak mudah menyerap materi yang ada, sehingga dapat mengerjakan soal-soal yang ada dengan benar. Semakin berkembangnya berbagai alat komunikasi modern terutama smartphone yang dikembangkan oleh berbagai vendor terkemuka di dunia. Hal ini juga berpengaruh dunia pendidikan dan pembelajaran di indonesia. Metode baru dalam pembelajaran pun dikemas secanggih mungkin, yaitu dapat mempermudah para siswa dalam memahami pelajaran. Dengan ini penulis melakukan penelitian dalam tahap mengembangkan sistem pembelajaran terbaru. Penelitian pengembangan ini bertujuan untuk menghasilkan media pembelajaran berbasis android, yang bisa membuat para siswa SD 5 Parittiga lebih tertarik untuk mengikuti pembelajaran. Dalam hal ini penulis berharap akan adanya pengembang yang bisa untuk mengembang aplikasi ini agar bisa membuat pembelajaran di indonesia lebih tertarik. Model pengembangan yang digunakan pada penelitian ini menggunakan bahasa pemrograman java eclipse.
\end{abstract}

Keywords-Aplikasi, Android, Pembelajaran.

\section{PENDAHULUAN}

Demi berkembangnya suatu jaman, Media dan teknologi memiliki pengaruh penting terhadap pendidikan. Contohnya, Handphone, PC tablet, komputer dan internet telah mempengaruhi proses pembelajaran sampai saat ini. Aturanaturan dari pendidik dan pembelajar telah berubah karena dipengaruhi media dan teknologi yang digunakan di dalam kelas. Banyak media pembelajaran yang dapat digunakan salah satu media yang digunakan yaitu Aplikasi Pembelajaran pada Gadget. Dalam media pembelajaran mampu melatih pengetahuan, keterampilan dan ketepatan dalam sistem pembelajaran dengan cara yang lebih menarik.
Perkembangan Telephon Seluler, manfaat dan modelnya mengalami perkembangan yang sangat pesat. Teknologi perangkat lunak yang digunakan telah menambah fungsi ponsel, yang dulu nya hanya dapat digunakan untuk menelepon dan SMS, Kini berubah menjadi smartphone. Dengan adanya smartphone dapat dijadikan sebagai media pembelajaran yang bersifat moveable.

Sekolah dasar merupakan tingkatan pendidikan yang mengajarkan berbagai pendidikan dasar. Pada tingkatan ini, didikan pembelajaran yang diajarkan oleh guru hanya sebatas pembelajaran dasar untuk meningkatkan pembelajaran para siswa dibutuhkan peranan para orang tua. Pada umumnya, para orang tua cukup sulit untuk membimbing anak-anaknya belajar, karena ketidaktertarikan anak yang merasa bosan dengan media belajar (buku). Untuk meningkatkan semangat anak belajar dengan media pembelajaran yang moveable (mudah dibawa kemana-mana) dan dengan tampilan yang menarik, diharapkan dapat membantu para orang tua untuk mengajak anak belajar di rumah dan membantu anak mudah menyerap materi yang ada, sehingga dapat mengerjakan soalsoal yang ada dengan benar.

Adapun penelitian yang terkait dengan aplikasi pembelajaran berbasis android yaitu Pertama penelitian dari Supriyanto, Dwi Joko dkk yang berjudul "Aplikasi Pembelajaran Matematika SMP Untuk Bekal Menghadapi UAN Berbasis Android" dengan menghasilkan perangkat lunak berupa paket ajar berbentuk aplikasi pembelajaran matematika SMP berbasis android yang dihasilkan, dapat menjadikan salah satu solusi untuk meningkatkan minat siswa smp untuk mempelajari dan memahami matematika SMP, karena di desain dengan menarik dan menggunakan teknologi android yang banyak digunakan di era modern.

Kedua penelitian dari Winata, Dinata yang berjudul "Rancang Bangun Aplikasi Pembelajaran Anak Usia Dini Berbasis Android" dengan menghasilkan Aplikasi Pembelajaran Anak Usia Dini berbasis Flash pada Android dengan dasar pemrograman ActionScript 3.0 ini telah 
berjalan baik pada perangkat Android dengan minimum sistem operasi Android 2.2 ( froyo ), Aplikasi Aplikasi Pembelajaran Anak Usia Dini ini cukup mudah digunakan oleh anak-anak sebagai panduan dalam pembelajaran, Materi yang disajikan menggunakan tampilan aplikasi yang menarik didukung dengan suara dalam pembelajaran, dan Materi yang diajarkan dalam aplikasi sangat sesuai dengan anak-anak prasekolah.

\section{TINJAUAN PUSTAKA}

\section{A. Android}

Android merupakan sebuah sistem operasi berbasis linux untuk perangkat mobile yang mencakup sistem operasi, middleware dan aplikasi. Awalnya Google Inc. membeli Android Inc. yang merupakan pendatang baru yang membuat piranti lunak untuk ponsel atau smartphone. Google Inc. membeli Android Inc. kemudian mengembangkan android dan dibentuklah Open Handset Alliance konsorsium dari 34 perusahaan peranti lunak, peranti keras dan telekomunikasi , termasuk Google, HTC, Motorola, Qualcomm, T-Mobile, dan Nvidia.

Pada saat perilisan perdana Android, 5 November 2007 , Android bersama Open Handset Alliance menyatakan mendukung pengembangan open source pada perangkat mobile. Di lain pihak, Google merilis kode - kode Android di bawah lisensi Apache, sebuah lisensi perangkat lunak dan open platform perangkat seluler. [6].

\section{B. Penelitian Sebelumnya}

Adapun penelitian sebelumnya dengan pembelajaran berbasis android sebagai berikut:

- Penelitian dari Supriyanto, Dwi Joko dkk yang berjudul "Aplikasi Pembelajaran Matematika SMP Untuk Bekal Menghadapi UAN Berbasis Android" dengan menghasilkan perangkat lunak berupa paket ajar berbentuk aplikasi pembelajaran matematika SMP berbasis android yang dihasilkan, dapat menjadikan salah satu solusi untuk meningkatkan minat siswa smp untuk mempelajari dan memahami matematika SMP, karena di desain dengan menarik dan menggunakan teknologi android yang banyak digunakan di era modern.

- Penelitian dari Winata, Dinata yang berjudul "Rancang Bangun Aplikasi Pembelajaran Anak Usia Dini Berbasis Android" dengan menghasilkan Aplikasi Pembelajaran Anak Usia Dini berbasis Flash pada Android dengan dasar pemrograman ActionScript 3.0 ini telah berjalan baik pada perangkat Android dengan minimum sistem operasi Android 2.2 (froyo), Aplikasi Aplikasi Pembelajaran Anak Usia Dini ini cukup mudah digunakan oleh anak-anak sebagai panduan dalam pembelajaran, Materi yang disajikan menggunakan tampilan aplikasi yang menarik didukung dengan suara dalam pembelajaran, dan Materi yang diajarkan dalam aplikasi sangat sesuai dengan anak-anak prasekolah.

- Penelitian dari Pamuji Eko yang berjudul "Pembuatan Aplikasi Pembelajaran Andromath Berbasis Android"dengan menghasilkan user bisa belajar tentang bangun ruang dan bangun datar secara mobile, belajar sambil bermain kuis, aplikasi Andromatah ini juga dilengkapi dengan kalkulator, agar dapat membantu user untuk melakukan perhitungan luas, keliling, dan volume.

\section{METODE PENELITIAN}

Model pengembangan perangkat lunak pada penelitian ini menggunakan model Waterfall. Berikut aliran metode penelitian yang digunakan:

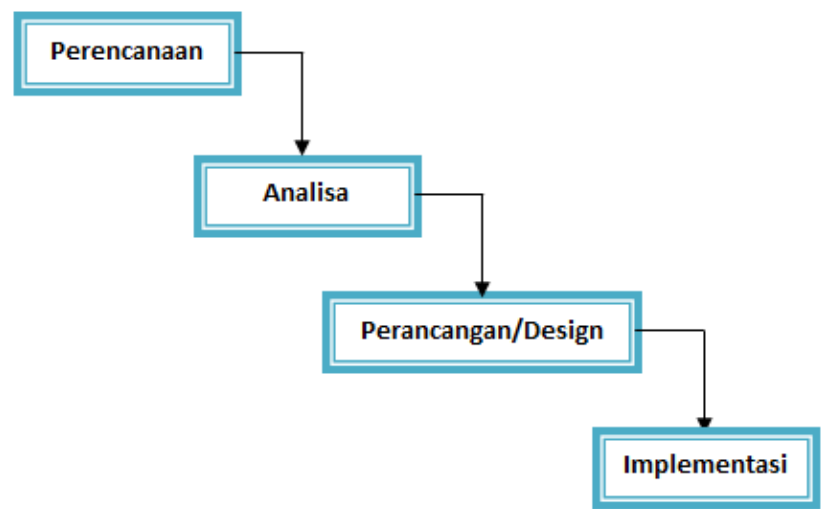

Gambar 1. Model Waterfall

\section{A. Analisa Masalah}

Dalam penyampaian pembelajaran yang diberikan guru terhadap siswa nya serta penyajian media pembelajaran yang saat ini digunakan yakni buku, terkadang membuat siswa merasa bosan untuk belajar. Pada beberapa siswa khusunya kelas 1 sekolah dasar yang mempelajari berbagai macam pembelajaran dasar seperti pengenalan huruf, pengenalan angka dan sebagainya, dibutuhkan media pembelajaran yang dapat menarik daya tarik siswa itu untuk belajar. Dengan adanya ketidaktertarikan siswa ini, dibutuhkan media alternatif bagi para guru dalam memberikan materi pembelajaran dasar siswa kelas 1 sekolah dasar pada SD Negeri 5 Parittiga. Media alternatif ini diharapkan dapat meningkatkan daya tarik siswa dalam belajar sehingga para siswa dapat dengan mudah memahami pembelajaran dasar yang telah disampaikan oleh guru. Selain itu, media ini juga dapat digunakan siswa dalam mengulangi pelajaran yang diajarkan guru di sekolah dan daapat dipelajari dirumah.

\section{B. Analisa Sistem Berjalan}

Berdasarkan topik yang penulis ambil yakni mengenai pembuatan aplikasi media pembelajaran pengenalan dasar 
kelas 1 Sekolah Dasar sebagai saran mempelajari berbagai macam pembelajaran dasar seperti mengenal huruf, mengenal angka mengenal warna, mengenal bentuk bangun datar pada SDN 1 Parittiga, maka perlu diketahui bagaimana proses pembelajaran yang ada sekarang di SDN 5 Parittiga. Pada umumnya proses pembelajaran ini selalu diajarkan di sekolah, dan penulis bertanya apakah kegiatan pembelajaran ini selalu diajarkan di sekolah, dan penulis bertanya apakah kegiatan pembelajaran ini dapat langsung dimengerti oleh siswa-siswi nya yang terkadang konsentrasi dan kurang ketertarikan siswa terhadap pembelajaran yang mononton ini perlu diadakannya pengulangan kembali pelajaran tersebut.

\section{Usecase Diagram}

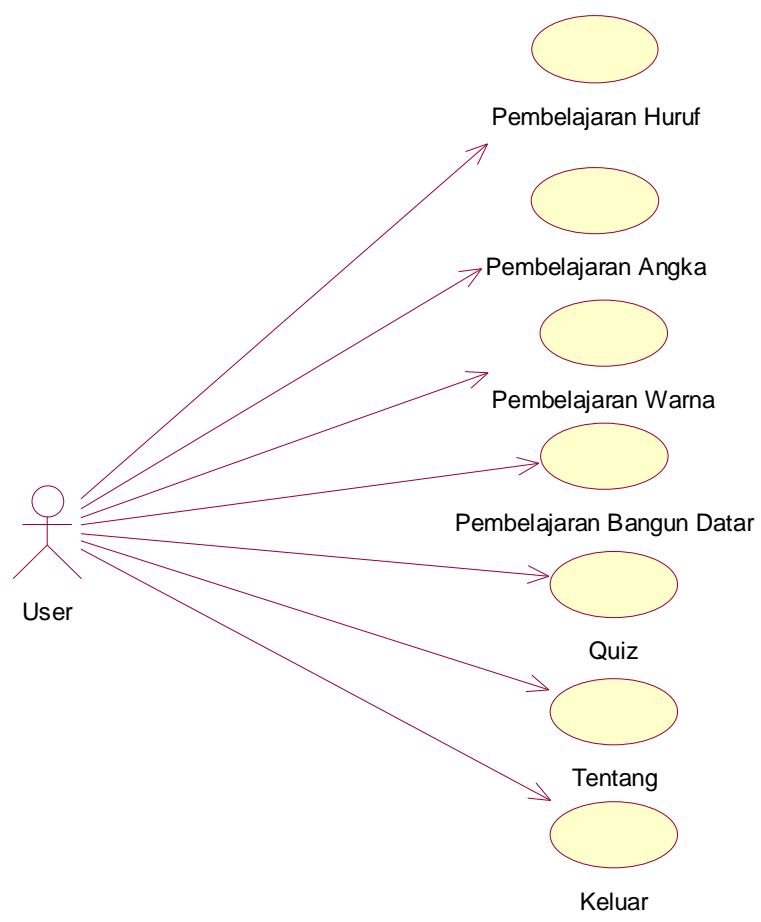

Gambar 2. Usecase Diagram

Deskripsi Usecase Diagram

Tabel 1. Penjelasan Use Case Diagram

\begin{tabular}{|c|l|l|}
\hline Aktor & Nama Use Case & \multicolumn{1}{|c|}{ Deskripsi Use Case } \\
\hline User & $\begin{array}{l}\text { Pembelajaran } \\
\text { Angka }\end{array}$ & $\begin{array}{l}\text { Use Case ini digunakan untuk } \\
\text { menampilkan pembelajaran angka } \\
\text { yang diinginkan }\end{array}$ \\
\hline User & $\begin{array}{l}\text { Pembelajaran } \\
\text { Huruf }\end{array}$ & $\begin{array}{l}\text { Use case ini digunakan untuk } \\
\text { menampilkan huruf yang } \\
\text { diinginkan }\end{array}$ \\
\hline User & $\begin{array}{l}\text { Pembelajaran } \\
\text { Warna }\end{array}$ & $\begin{array}{l}\text { Use case ini digunakan untuk } \\
\text { menampilkan pembelajaran nama } \\
\text { warna yang dinginkan }\end{array}$ \\
\hline
\end{tabular}

\begin{tabular}{|c|l|l|}
\hline Aktor & Nama Use Case & \multicolumn{1}{|c|}{ Deskripsi Use Case } \\
\hline User & $\begin{array}{l}\text { Pembelajaran } \\
\text { Bentuk Bangun } \\
\text { Datar }\end{array}$ & $\begin{array}{l}\text { Use case ini digunakan untuk } \\
\text { menampilkan pembelajaran } \\
\text { Bentuk Bangun Datar yang } \\
\text { diinginkan }\end{array}$ \\
\hline User & Tentang & $\begin{array}{l}\text { Use case ini digunakan untuk } \\
\text { menampilkan informasi pembuat } \\
\text { aplikasi }\end{array}$ \\
\hline User & Exit & $\begin{array}{l}\text { Use case ini digunakan untuk } \\
\text { keluar dari aplikasi pembelajaran }\end{array}$ \\
\hline
\end{tabular}

\section{HASIL DAN PEMBAHASAN}

\section{A. Tampilan Layar Splash}

ScreenTampilan layar Splash screen ini adalah tampilan awal dijalankannya aplikasi pembelajaran dasar kelas 1 berbasis android pada SDN 5 Parittiga.

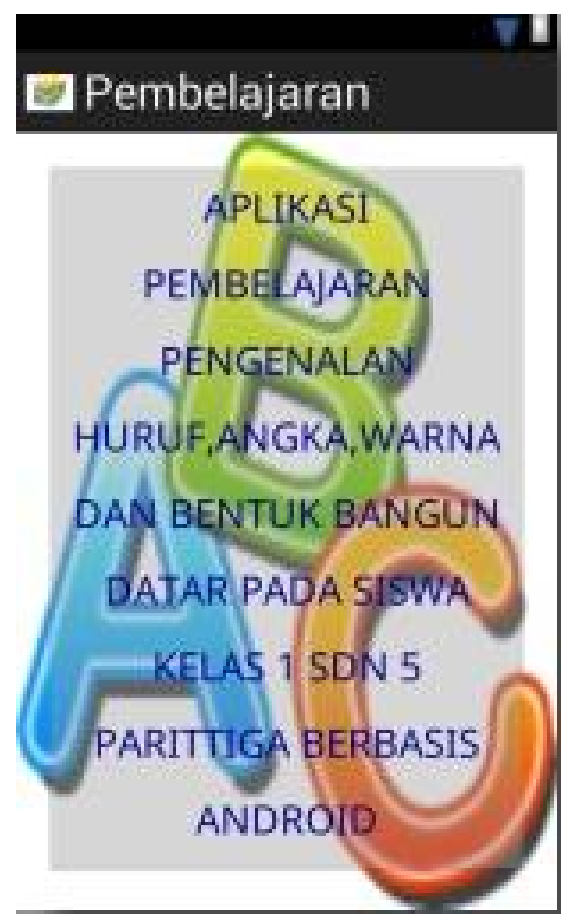

Gambar 3. Layar Splash Screen

\section{B. Tampilan Layar Menu Utama}

Tampilan layar menu utama adalah tampilan layar utama yang terdiri dari beberapa button yakni huruf, angka, warna, bangun datar, tentang dan keluar. 


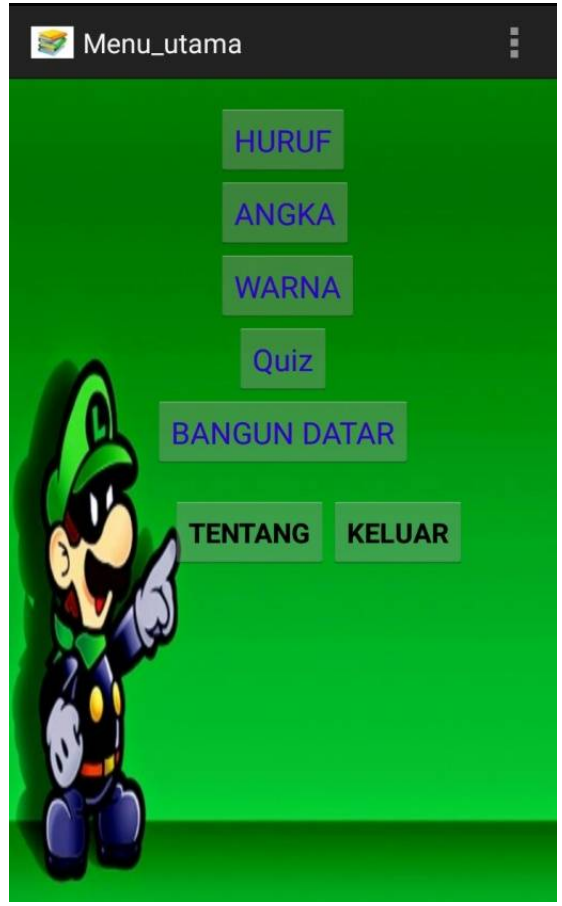

Gambar 4. Layar Menu Utama

\section{Tampilan Layar Menu Huruf}

Tampilan layar menu angka adalah tampilan yang berisikan huruf-huruf yang terdiri dari A sampai Z. menu huruf ini akan mengeluarkan audio atau suara ketika ditekan pada button huruf tersebut.

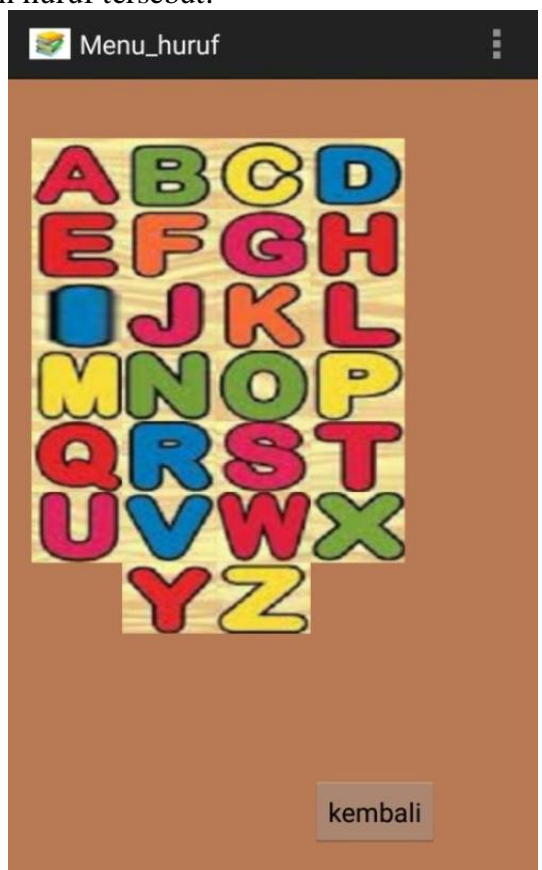

Gambar 5. Layar Menu Huruf

\section{Tampilan Layar Menu Angka}

Tampilan layar menu angka adalah tampilan yang berisikan huruf-huruf yang terdiri dari 0 sampai 9. menu angka ini akan mengeluarkan audio atau suara ketika ditekan pada button angka tersebut.

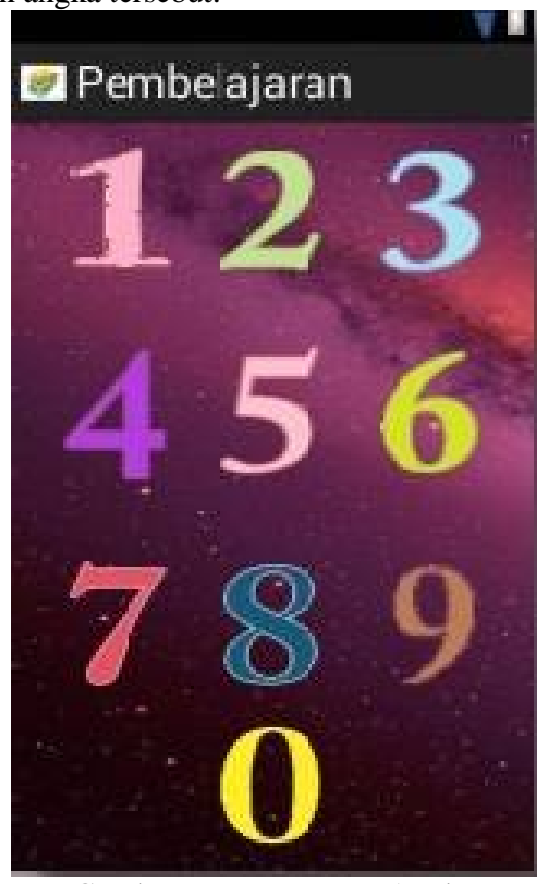

Gambar 6. Layar Menu Angka

\section{E. Tampilan Layar Menu Warna}

Tampilan layar menu warna adalah tampilan yang berisikan warna-warna yang terdiri 9 warna. menu warna ini akan mengeluarkan audio atau suara ketika ditekan pada button warna tersebut.
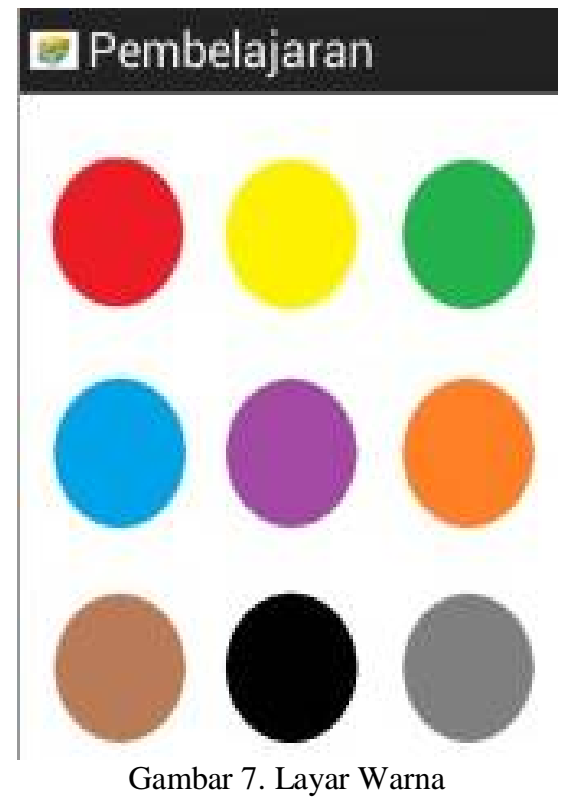


\section{F. Tampilan Layar Menu Bangun Datar}

Tampilan layar Bangun Datar adalah tampilan yang berisikan Bangun Datar yang terdiri dari 7 bentuk bangun datar. menu Bangun Datar ini akan mengeluarkan audio atau suara ketika ditekan pada button Bangun Datar tersebut.

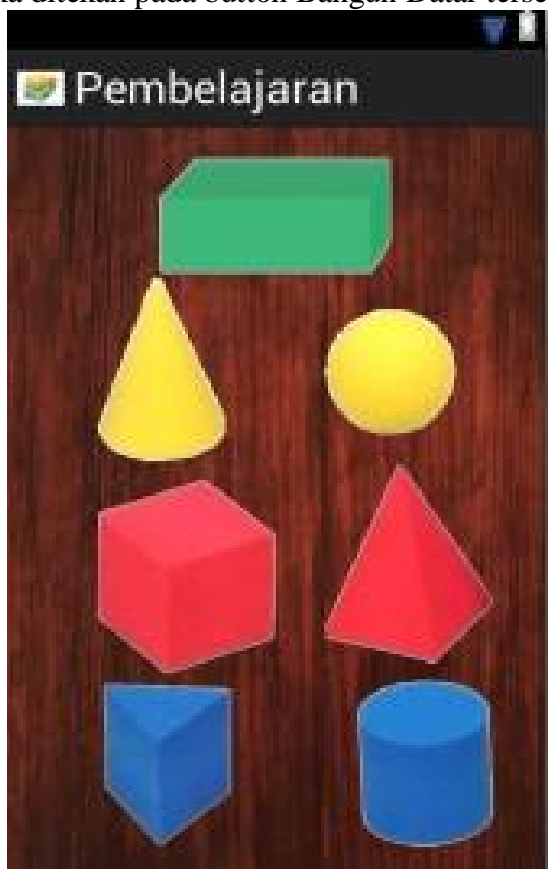

Gambar 8. Bangun Datar

\section{G. Tampilan Layar Quiz}

Tampilan layar quiiz ini berisi tentang latihan soal:

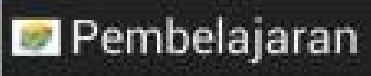

\section{Angka Berapakah Di}

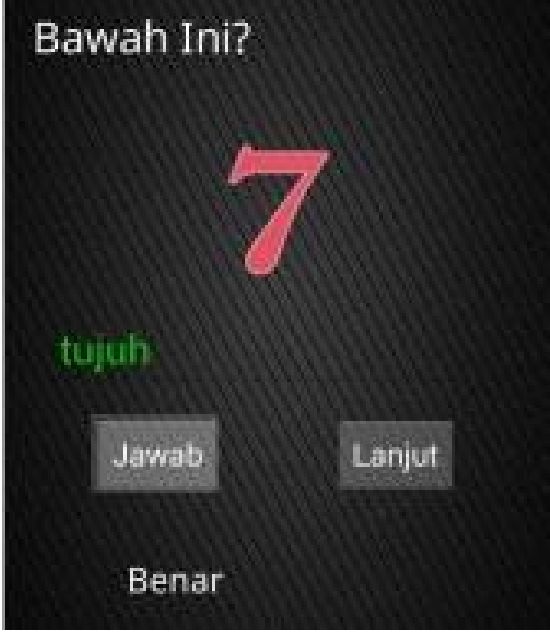

Gambar 9. Layar Quiz

\section{H. Tampilan Layar Menu Tentang}

Tampilan layar tentang ini berisi tentang aplikasi pembelajaran pengenalan dasar SDN 5 Parittiga.

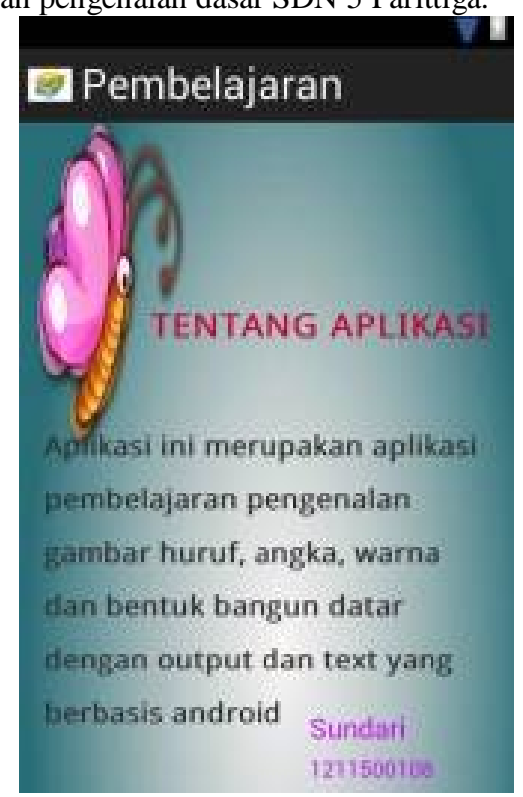

Gambar 10. Layar Tentang

\section{V.PENUTUP}

Setelah melakukan analisa, pengamatan serta implementasi secara langsung terhadap aplikasi, maka penulis dapat menarik kesimpulan tentang Pada Siswa SDN 5 Parittiga Berbasis Android dirancang dan dibuat dengan eclipse dan Adobe photoshop 7.0 sehingga aplikasi ini dapat dijadikan komplemen atau sebagai media pelengkap dalam rangka menghilangkan rasa bosan murid ketika mereka belajar. Aplikasi ini dapat digunakan kapan saja dan dimana saja.Aplikasi Pembelajaran Pengenalan Huruf, Angka, Warna dan Bentuk Bangun Datar

\section{DAFTAR PUSTAKA}

[1] Fatta, H. A. 2007. Analisis dan Perancangan Sistem Informasi untuk Keunggulan Bersaing Perusahaan dan Organisasi Modern. Yogyakarta: Andi.

[2] Hermawan, B. 2007. Menguasai JAVA 2 \& Object Oriented Programming. Yogyakarta: Andi.

[3] Jubilee Enterprise. 2013. Pemrograman Android Untuk Pemula. Jakarta: Elex Media Komputindo.

[4] Owens, M. 2006. The Definitive Guide to SQLite . United States of America: Apress.

[5] Raharjo, B. 2011. Belajar Otodidak Membuat Database Menggunakan MySQL. Bandung: Informatika.

[6] Safaat, N. 2012. Android Pemrograman Aplikasi Mobile Smartphone dan Tablet PC Berbasis Android. Bandung: Informatika.

[7] Sakur, S. B. 2011. Pemrograman Berorientasi Objek-Konsep \& Implementasi. Yogyakarta: Andi.

[8] Shortcourse. 2013. Android Programming with Eclipse. Semarang: Wahana Komputer.

[9] Winata, Rian. 2013. Rancang Bangun Aplikasi Pembelajaran Anak Usia Dini Berbasis Android. UIN Sultan Syarif Kasim Riau, Pekan Baru. 